\title{
Anti-Neuroinflammatory Effects of Ixeris dentata Nakai against Lipopolysaccharide-Induced BV-2 Microglial Cells via Suppressing NF-kB Signaling
}

\author{
Hyun Kang \\ Department of Medical Laboratory Science, College of Health Science, Dankook University, Cheonan-si, Chungnam, 330-714, \\ Republic of Korea \\ *For correspondence: Email: hyunbio@gmail.com, hkang@dankook.ac.kr
}

Received: 24 July 2014

Revised accepted: 14 September 2014

\begin{abstract}
Purpose: To investigate the suppressive effects of I. dentata on lipopolysaccharide (LPS)-induced neuroinflammatory responses in BV-2 microglia and its antioxidant effects.

Methods: Cell viability and free radical scavenging activities were performed using 3-(4, 5dimethylthiazol-2-yl)-2, 5- diphenyl-tetrazolium bromide (MTT) and 1, 1-diphenyl-2-picryl-hydrazyl (DPPH) assay, respectively. LPS $(1 \mu \mathrm{g} / \mathrm{ml})$ was used to stimulate BV-2 microglia. Pro-inflammatory mediators such as nitric oxide (NO), inducible NO synthase (iNOS), cyclooxygenase (COX)-2, tumor necrosis factor-alpha (TNF- $\alpha$ ), and nuclear factor-kappa B (NF-KB) were measured using western blotting and enzyme-linked immunosorbent assay.

Results: Treatment with I. dentata extract (ID-EA) significantly scavenged the DPPH radicals with IC50 value at $44.64 \pm 2.64 \mu \mathrm{g} / \mathrm{ml}(p<0.01$ at $50 \mu \mathrm{g} / \mathrm{ml})$. The increased levels of $N O(23.32 \pm 2.84 \mu \mathrm{M})$ and protein expressions of iNOS and COX-2 were inhibited by ID-EA extract in LPS-stimulated BV-2 cells. Increased pro-inflammatory cytokines such as TNF- $\alpha$ and IL-6 were also suppressed by ID-EA extract significantly $(p<0.001$ at $80 \mu \mathrm{g} / \mathrm{ml})$. Further, ID-EA extract blocked the expression of NF-KB activation in LPS-stimulated BV-2 cells.

Conclusion: Data from this study suggest that ID-EA extract possesses antioxidant effect and inhibits increased production of pro-inflammatory responses in LP5-stimulated BV-2 cells by suppressing NF-KB activation pathway. The significant inhibition of neuroinflammatory responses in stimulated microglial cells together with strong antioxidant activity may indicate that ID-EA can be developed as a therapeutic compound for treating neuroinflammatory diseases.
\end{abstract}

Keywords: Chenopodiaceae, Microglia, Lipopolysaccharide, Neuroinflammation, Antioxidant

Tropical Journal of Pharmaceutical Research is indexed by Science Citation Index (SciSearch), Scopus, International Pharmaceutical Abstract, Chemical Abstracts, Embase, Index Copernicus, EBSCO, African Index Medicus, JournalSeek, Journal Citation Reports/Science Edition, Directory of Open Access Journals (DOAJ), African Journal Online, Bioline International, Open-J-Gate and Pharmacy Abstracts

\section{INTRODUCTION}

Neuroinflammation is a complex response to an exterior challenge or cellular injury in the central nervous system. Microglial cells, the resident innate immune cells in the brain, have been implicated as active contributors to neuronal damage in neurodegenerative diseases [1]. Microglial activation leads to the release of a complex array of pro-inflammatory moderators, cytokines and neurotoxic compounds such as nitric oxide (NO), inducible NO synthase (iNOS), Cyclooxygenase (COX) -2, tumor necrosis factor (TNF)a, interleukin (IL)-1b, IL-6, and reactive oxygen species contributing to the pathogenesis of many neuroinflammatory diseases [1,2]. Further transcription factors such as nuclear factor-kappa B (NF-kB) play important roles in 
the signaling pathways that lead to inflammatory activation of microglia [3]. Thus, inhibition of microglial activation and the resulting reduced neuroinflammatory responses would be an effective therapeutic strategy to alleviate the progression of brain diseases.

Ixeris dentata var. albiflora Nakai, from the family Astaraceae, is a medicinal herbal plant used traditionally in Asian countries to treat stomach upsets, diabetes, tumors and liver diseases $(4,5)$. Pharmacologically, I. dentata has been reported to possess anti-mutagenic, anti-cancer, hypoglycemic, hypocholesterolemic and oxidative stress inhibiting properties [6-8]. However, the beneficial effect of I. dentata on neuroinflammation in activated microglial cells has not been studied. Therefore in the present study we explored the anti-neuroinflammatory effects of $I$. dentata on lipopolysaccharide (LPS)stimulated BV-2 microglial cells.

\section{EXPERIMENTAL}

\section{Plant material and preparation of I. dentata root extract}

The roots of $I$. dentata collected during the month of August to September were obtained from the local herbal market, Seoul, South Korea. The collected material was authenticated by Prof. Jong-Bo Kim, a taxonomist at Konkuk University, Korea and a voucher specimen (ID-DKU2013) has been kept in our laboratory herbarium, Dankook University, Korea for future reference. To obtain the $I$. dentata extract, roots were washed to remove debris and air dried for two days. The dried roots were then pulverized into powder using electric blender (Model 4250 Braun Germany). Fifty grams of powdered roots were extracted with three volumes of $80 \%$ ethanol with mixing at room temperature for $24 \mathrm{~h}$. The extract was filtered and lyophilized to obtain ethanol extract concentrate $(\mathrm{EtOH})$ of $I$. dentata (Yield: $17.5 \mathrm{~g}$ ). The $\mathrm{EtOH}$ extract of I. dentata root extract $(10 \mathrm{~g})$ was re-suspended in water:EtOH $(9: 1, v / v)$ and partitioned in turn with n-hexane, chloroform, ethylacetate $(E A)$ and nbutanol solvents to obtain a final yield of 0.48 , $0.10,0.47$ and $1.27 \%$, respectively. The EA fraction of $I$. dentata (ID-EA) extract with strong antioxidant property in our preliminary evaluation was used for further studies. The ID-EA extract was dissolved in sterile distilled water, filtered on $0.22 \mu \mathrm{m}$ syringe filters and stored at $-20{ }^{\circ} \mathrm{C}$ until use. All reagents used in this study were of highest grade available commercially.

\section{Free radical scavenging activity}

The radical scavenging activity of ID-EA extract was measured using a stable radical 2, 2diphenyl-1-picrylhydrazyl (DPPH, Sigma-Aldrich, St. Louis, MO, USA). The scavenging effects were evaluated by employing a reaction mixture constituted with aliquots of the ID-EA extract and a DPPH methanolic solution as described previously [9]. Briefly, a sample solution of $60 \mu \mathrm{L}$ of each ID-EA extract, was added to $60 \mu \mathrm{L}$ of $\mathrm{DPPH}(60 \mu \mathrm{M})$ in methanol. After mixing vigorously for $10 \mathrm{~s}$, the mixture was then transferred into a $100 \mu \mathrm{L}$ Teflon capillary tube and the scavenging activity of each sample on DPPH radical was measured using a JES-FA ESR spectrometer (Jeol Ltd, Tokyo, Japan). A spin adduct was measured on an ESR spectrometer exactly after $2 \mathrm{~min}$. Experimental conditions were as follows: central field, 3,475 G; modulation frequency, $100 \mathrm{kHz}$; modulation amplitude, $2 \mathrm{G}$; microwave power, $5 \mathrm{~mW}$; gain, $6.3 \times 10^{5}$, and temperature, $298 \mathrm{~K}$.

\section{Cell culture and viability assay}

BV-2 microglia cells were cultured at $37{ }^{\circ} \mathrm{C}$ in 5 $\% \mathrm{CO}_{2}$ in DMEM (Invitrogen, Carlsbad, CA, USA) supplemented with $5 \%$ FBS (Hyclone, Logan, UT, USA) and antibiotics (Invitrogen). For viability assay, 3-(4, 5-dimethylthiazol-2-yl)-2, 5diphenyl-tetrazolium bromide (MTT, SigmaAldrich, St. Louis, MO, USA) assay was used as described previously [10]. Briefly, BV-2 cells were plated onto 96 well plates and exposed to ID-EA extract. MTT was added to each well then incubated for additional $2 \mathrm{~h}$ in the dark at $37^{\circ} \mathrm{C}$. The medium was then aspirated from the wells and the blue formazan product obtained was dissolved in DMSO. The plates were analyzed at $570 \mathrm{~nm}$ using a microplate reader (Tecan Trading AG, Switzerland). Each experiment was conducted in triplicate. Cell viability (\%) was calculated as the ratio of the absorbance of extract-treated sample to that of the non-treated sample, expressed as a percentage.

In all other experiments, the cells were pretreated with ID-EA extract at indicated concentrations $(10,20$ and $40 \mu \mathrm{g} / \mathrm{ml})$ for $1 \mathrm{~h}$ before the addition of LPS $(1 \mu \mathrm{g} / \mathrm{mL}$, SigmaAldrich, St Louis, MO, USA) in serum free DMEM. An equal volume of sterile water was added to all control treatments.

\section{Immunoblot analysis and antibodies}

Cells were washed in cold PBS three times and lysed in a buffer containing $50 \mathrm{mM}$ Tris- $\mathrm{HCl}, \mathrm{pH}$ 
$7.4, \quad 1 \% \quad(v / v) \quad N P-40, \quad 0.25 \%$ sodium deoxycholate, $150 \mathrm{mM} \mathrm{NaCl}, 1 \mathrm{mM}$ EDTA, 25 $\mathrm{mM} \mathrm{NaF}, 2 \mathrm{mM} \mathrm{Na}_{3} \mathrm{VO}_{4}$ and protease inhibitor cocktail (Complete MiniTM, Roche, Mannheim, Germany) at $4{ }^{\circ} \mathrm{C}$. The lysate was clarified by centrifugation at $10,000 \mathrm{~g}$ for $20 \mathrm{~min}$ at $4{ }^{\circ} \mathrm{C}$ to remove insoluble components. Cell lysates were normalized for protein content using BCA reagent (Pierce, Rockford, IL, USA). Equal amounts of protein were loaded onto $10 \%$ PAGE gels and separated by standard SDS-PAGE procedure. Proteins were transferred to an NC membrane ( $S$ \& $S$, Dassel, Germany) and blocked with $5 \%$ non-fat dry milk in TBS. To detect protein expression, the blots were probed with the specific antibodies against iNOS, COX-2 and NF-KB followed by the secondary antibodies coupled to horseradish peroxidase (Bio-Rad, Herculus, CA, USA). The internal control used in our study was $\beta$-actin. The immunoreactive proteins on the membrane were detected by chemiluminescence using the West-Save substrate (Lab-Frontier, Seoul, Korea) on X-ray film. The antibodies against iNOS, COX-2, NF-kB and $\beta$-actin were purchased from Cell Signaling Technology INC. (Beverly, MA, USA).

\section{NO assay}

Production of NO was assayed by measuring the levels of nitrite in the culture supernatant using colorimetric assay with Griess reagent [11]. Briefly, BV- 2 cells $\left(2 \times 10^{5}\right.$ cells $\left./ \mathrm{mL}\right)$ were seeded in 6-well plates in $500 \mu \mathrm{L}$ complete culture medium and treated with the ID-EA extract at indicated concentrations $(10,20$ and $40 \mu \mathrm{g} / \mathrm{mL}$ ) for $1 \mathrm{~h}$ prior to stimulation with LPS $(1 \mu \mathrm{g} / \mathrm{mL})$ for 2 h. Culture supernatant $(50 \mu \mathrm{L})$ was reacted with an equal volume of Griess reagent $(0.1 \%$ naphthylethylenediamine and $1 \%$ sulfanilamide in $5 \% \mathrm{H}_{3} \mathrm{PO}_{4}$ ) in 96-well plates at room temperature in the dark. Nitrite concentrations were determined by using standard solutions of sodium nitrite prepared in the culture medium. The absorbance was determined at $540 \mathrm{~nm}$ using a microplate reader (Tecan).

\section{TNF- $\alpha$ and IL-6 assay}

BV-2 microglia cells $\left(1 \times 10^{5}\right.$ cells/well) were cultured in 96 well plates and treated with the IDEA extract at the indicated concentrations for $1 \mathrm{~h}$ and stimulated with LPS $(1 \mu \mathrm{g} / \mathrm{mL})$. At $4 \mathrm{~h}$ post LPS treatment, the cells were collected and the supernatants were evaluated for TNF- $\alpha$ and IL-6 contents using a murine TNF- $\alpha$ and IL- 6 ELISA kit from BD Biosciences, respectively (San Jose,
CA, USA) according to the manufacturer's instructions.

\section{Statistical analysis}

All data are represented as the mean \pm S.E.M of at least three independent experiments. Statistical analyses were performed using SAS statistical software (SAS Institute, Cray, NC, USA) using one-way analysis of variance, followed by Dunnett's multiple range tests. $P$ value $<0.05$ was considered statistically significant.

\section{RESULTS}

\section{DPPH radical scavenging activity of ID-EA extract}

As shown in Fig. 1A, ID-EA showed significant $\mathrm{DPPH}$ radical scavenging activity in a concentration-dependent manner. The maximum scavenging activity was observed at $100 \mu \mathrm{g} / \mathrm{mL}$ of concentration $(p<0.001)$. However, ID-EA extract at concentration of 10 and $50 \mu \mathrm{g} / \mathrm{mL}$ also showed significant scavenging of DPPH radicals ( $p<0.05$ and $p<0.01$ at 10 and $50 \mu \mathrm{g} / \mathrm{mL}$, respectively). The concentration needed for 50 $\%$ inhibition of DPPH radical by ID-EA extract was $44.64 \pm 2.64 \mu \mathrm{g} / \mathrm{mL}$. The ESR spectroscopy data is represented in Fig $1 \mathrm{~B}$.

\section{Effect of ID-EA and/or LPS on BV-2 cell viability}

As shown in Fig. 2, treatment with LPS $(1 \mu \mathrm{g} / \mathrm{mL})$ with or without ID-EA extract at various concentrations $(10-100 \mu \mathrm{g} / \mathrm{mL})$ did not affect the overall cell viability nor did they exhibit any cytotoxicity on BV-2 microglia cells.

\section{Effect of ID-EA extract on LPS-induced NO production in BV-2 cells}

$\mathrm{NO}$ is one of the important inflammatory mediators produced by activated microglia. To study the effect of ID-EA extract on LPSstimulated NO release, BV-2 microglia were treated with various concentrations of ID-EA (10, 20 and $40 \mu \mathrm{g} / \mathrm{ml}$ ) for $30 \mathrm{~min}$ prior to LPS (1 $\mu \mathrm{g} / \mathrm{mL}$ ) stimulation for $4 \mathrm{~h}$. NO production by LPS-activated cells was found to be significantly inhibited by ID-EA extract in a concentrationdependent manner (Fig 3). 
A

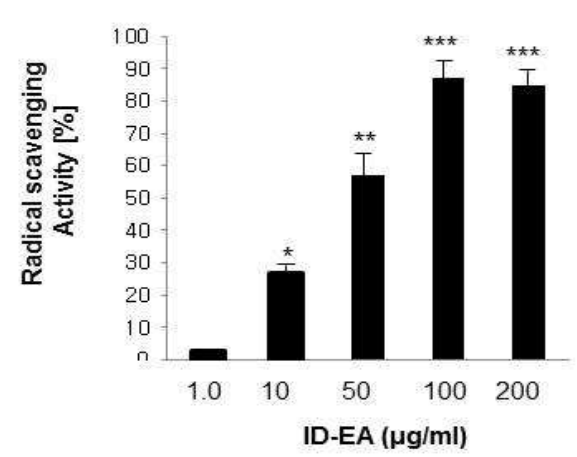

B

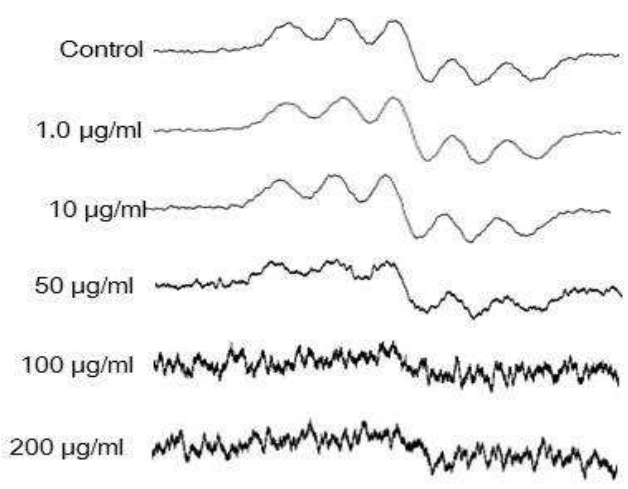

Fig 1: Effect of ID-EA extract on DPPH radical scavenging activity. The capacity to scavenge DPPH free radical by different concentrations of ID-EA (A) and ESR spectra $(B)$ is shown. The scavenging activity of ID-EA extract on DPPH radical was measured using a JES-FA ESR spectrometer. A spin adduct was measured on an ESR spectrometer exactly 2 min later. Data are presented as the mean \pm S.E.M. $(n=3)$ for three independent experiments; ${ }^{*} p<0.05,{ }^{* *} p<0.01$ and ${ }^{* * *} p<0.001$, when compared with control group by one-way analysis of variance, followed by Dunnett's multiple range tests. ID-EA: Ixeris dentata-ethylacetate

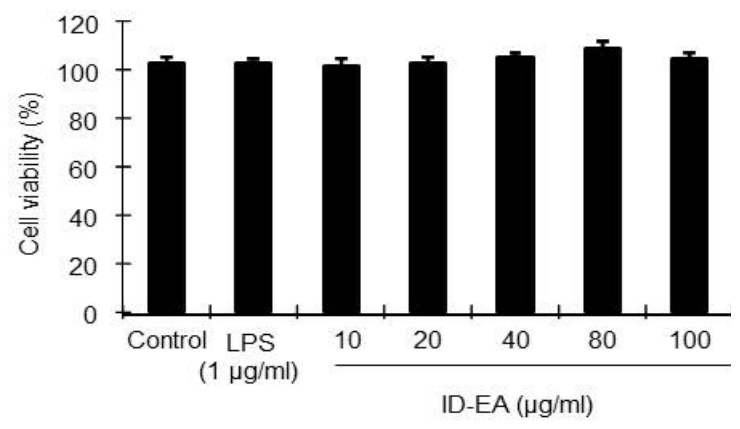

Fig 2: Effects of ID-EA extract on BV-2 microglial cell viability. Viability in ID-EA extract-treated cells was determined using MTT assay in the presence or absence of LPS $(1 \mu \mathrm{g} / \mathrm{mL})$. The results are depicted as percentage of control samples. Data are presented as the mean \pm S.E.M. $(n=3)$ for three independent experiments. ID-EA: Ixeris dentata-ethylacetate; LPS: Lipopolysaccharide

\section{Effect of ID-EA extract on LPS-induced iNOS and COX expression}

To know the effect of ID-EA extract on iNOS and COX-2 protein expressions, BV-2 cells were stimulated with LPS $(1 \mu \mathrm{g} / \mathrm{mL})$ in the presence or absence of ID-EA $(10,20$ and $40 \mu \mathrm{g} / \mathrm{mL})$. ID-EA extract exhibited a broad spectrum of inhibitory effect on the expression of pro-inflammatory mediators and reduced the LPS-stimulated increase of protein expression such as iNOS and COX-2 in a concentration-dependent manner (Fig 4).

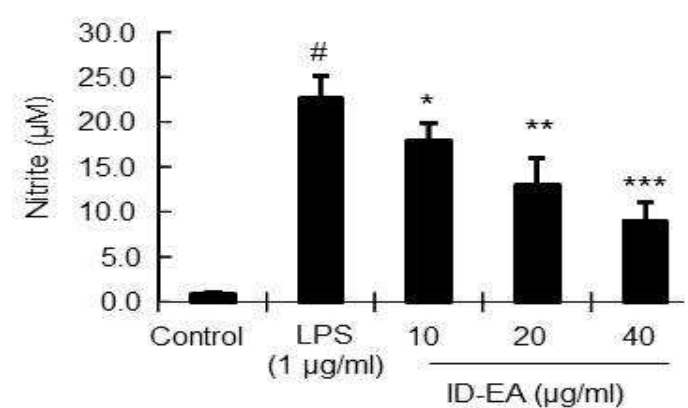

Fig. 3: Effect of ID-EA extract on NO Production in LPS-stimulated BV-2 microglial cells. BV-2 cells were treated with ID-EA at various concentrations $(10,20$ and $40 \mu \mathrm{g} / \mathrm{mL}$ ) with or without LPS $(1 \mu \mathrm{g} / \mathrm{mL})$ for $4 \mathrm{~h}$. The nitrite in the culture supernatant was evaluated using Griess reagent. Data are presented as the mean \pm S.E.M. $(n=3)$ for three independent experiments. ${ }^{\#} \mathrm{p}<0.001$, when compared with control group; * $p<$ $0.05,{ }^{* *} p<0.01$ and ${ }^{* * *} p<0.001$, when compared with LPS alone treated group by one-way analysis of variance, followed by Dunnett's multiple range tests. ID-EA: Ixeris dentata-ethylacetate, LPS: Lipopolysaccharide

\section{Effects of ID-EA extract on TNF- $\alpha$ and IL-6 levels in LPS-stimulated BV-2 cells}

As shown in Fig 5, TNF- $\alpha$ and IL-6 levels were increased significantly after LPS treatment (1 $\mu \mathrm{g} / \mathrm{mL}$ ) when compared to those in untreated cells $(p<0.001)$. However, ID-EA extract $(10,20$ and $40 \mu \mathrm{g} / \mathrm{mL}$ ) significantly inhibited these proinflammatory cytokines (Fig 5A and B) in a concentration-dependent manner in LPSstimulated BV-2 cells $(p<0.05$ at $10 \mu \mathrm{g} / \mathrm{mL}, p<$ 0.01 at $20 \mu \mathrm{g} / \mathrm{mL}$ and $p<0.001$ at $40 \mu \mathrm{g} / \mathrm{mL}$, respectively). 


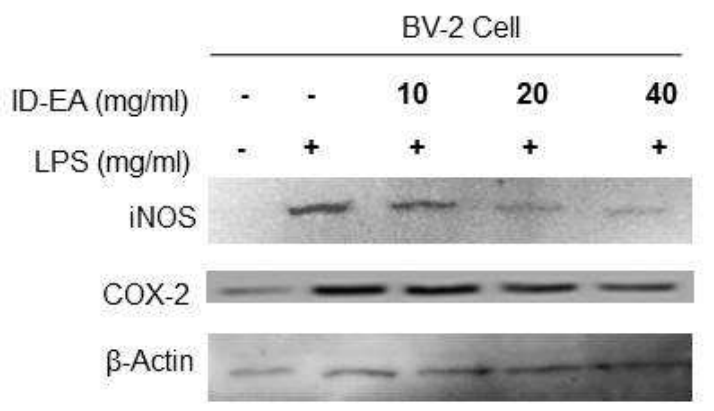

Fig. 4: Effect of ID-EA extract on iNOS and COX-2 expressions in LPS-stimulated BV-2 microglial cells. The expression levels of iNOS and COX-2 in LPSstimulated BV-2 cells by various concentrations (10, 20 and $40 \mu \mathrm{g} / \mathrm{mL}$ ) of the ID-EA was evaluated by immunoblot analyses with the specific antibodies against iNOS and COX-2. The internal control used was $\beta$-actin. ID-EA: Ixeris dentata-ethylacetate, LPS: Lipopolysaccharide, iNOS: inducible nitric oxide synthase COX-2: Cyclooxygenase
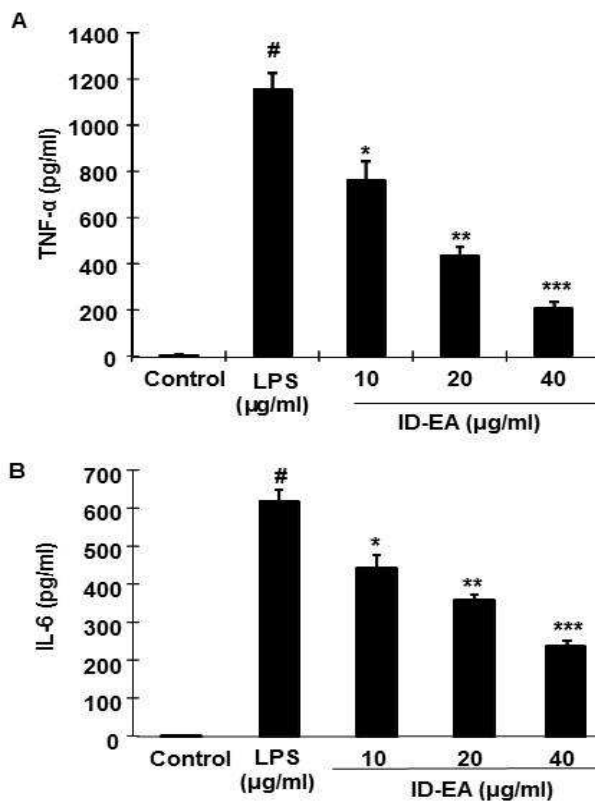

Fig 5: Effect of ID-EA on pro-inflammatory cytokine TNF- $\alpha$ and IL- 6 production in LPS-stimulated BV-2 cells. BV-2 cells were treated with ID-EA extract at indicated concentrations (10, 20 and $40 \mu \mathrm{g} / \mathrm{mL}$ ) with or without LPS $(1 \mu \mathrm{g} / \mathrm{mL})$ for $4 \mathrm{~h}$. The TNF- $\alpha$ and IL- 6 in the culture supernatant was evaluated using a murine TNF- $\alpha$ and IL- 6 ELISA kits, respectively, from BD Sciences according to the manufacturer's instruction. Data are presented as the mean $\pm \operatorname{SEM}(n=3)$ for three independent experiments. ${ }^{\#} p<0.001$, when compared with control group; ${ }^{*} p<0.05,{ }^{* *} p<0.01$, ${ }^{* * *} p<0.001$, compared with LPS alone treated group; ID-EA = Ixeris dentata-ethylacetate, LPS = lipopolysaccharide, TNF- $\alpha=$ tumor necrosis factor-alpha, IL-6 $=$ interleukin- 6

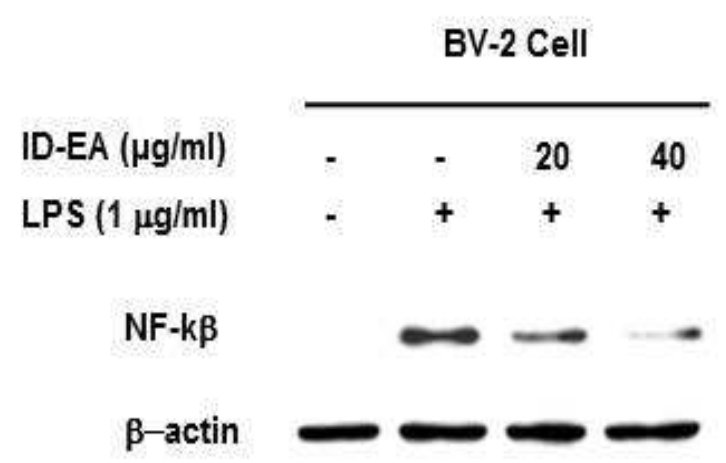

Fig 6: Effect of ID-EA on NF-kB activity in LPSstimulated BV2 microglia. BV-2 microglia cells were stimulated with $1 \mu \mathrm{g} / \mathrm{mL}$ of LPS in the absence or presence of the ID-EA extract (20 and $40 \mu \mathrm{g} / \mathrm{mL})$ that had been added $1 \mathrm{~h}$ before the stimulation. LPS stimulated NF-KB activation and increased expression was assayed by Western blot at $2 \mathrm{~h}$. Data are presented as the mean \pm S.E.M. $(n=3)$ for three independent experiments; ID-EA = Ixeris dentataethylacetate, LPS = lipopolysaccharide, NF-kB = nuclear factor kappa-B

ID-EA inhibited NF-kB activation in LPSstimulated BV-2 microglial cells

Expression of a number of pro-inflammatory cytokines and iNOS is controlled by NF-KB. Stimulation of cells with LPS $(1 \mu \mathrm{g} / \mathrm{mL})$ induced the marked activation of NF-KB. However, ID-EA extract inhibited the LPS-induced NF-KB activation in a concentration-dependent manner (Fig 6).

\section{DISCUSSION}

One of the critical players in brain inflammation is the uncontrolled activation of microglia distributed ubiquitously in the central nervous system which contributes to neuroinflammatorymediated neurodegeneration [1,12]. Microglial activation is the starting point for elevated levels of a wide array of potentially neurotoxic molecules including pro-inflammatory cytokines and neurotoxic reactive oxygen species [2]. It was well documented that microglial cells can be stimulated by LPS triggering the production of inflammatory mediators, cytokines and leukotriene [13]. Therefore, LPS-induced inflammatory mediators in vitro can be considered as one of the important tools to evaluate anti-neuroinflammatory agents.

Overproduction of $\mathrm{NO}$ and pro-inflammatory cytokines released by activated microglia induces neuronal death and damage to neighboring neurons in the brain. The microglia- 
mediated neurotoxicity has been demonstrated in many in vitro and in vivo investigations $[14,15]$. COX-2 and iNOS are inducible forms of enzymes which are up regulated in activated microglia in response to inflammatory challenge. The induction and regulation of these mediators are tightly coupled and thought to contribute to the pathogenesis of various diseases, including neurodegenerative diseases [16]. Other molecules that are secreted by stimulated microglial cells include TNF- $\alpha$ and interleukin, both of which can cause neuronal cell death both directly and indirectly via the induction of $\mathrm{NO}$ and free radicals in microglial cells [17].

In agreement with the previous reports on signaling pathways underlying microglial activation $[14,15]$, we observed that inflammatory mediators such as NO, iNOS and COX-2 and pro-inflammatory cytokines such as TNF- $\alpha$ and IL-6 were enhanced by LPS-stimulation in BV-2 microglial cells. However, ID-EA extract markedly suppressed the LPS-stimulated BV-2 microglial cell activation characterized by increased production of NO, iNOS and COX-2. In addition ID-EA extract inhibited the LPS-stimulated increase of the proinflammatory cytokines TNF- $\alpha$ and IL-6. This reduction was dose dependent and did not result from the cytotoxic effect of the extract.

The key inflammatory signaling mediator NF-кB was known to be involved in neuroinflammation. The promoters of the inflammatory genes iNOS and COX-2 contain NF-kB binding regions and the expression of these enzymes can be regulated by the activation of NF-KB by LPS [18]. Consistent with the earlier report, our study also showed marked increase in NF-kB activation when stimulated with LPS $(1 \mu \mathrm{g} / \mathrm{ml})$ in BV-2 cells. However this activation was suppressed by IDEA extract treatment of BV-2 cells. Therefore, the inhibitory effect of ID-EA extract on iNOS and COX-2 expression might be attributed to inhibition of NF-kB activation and may conclude that NF-kB is a major target of ID-EA extract.

The mechanism of neuroinflammation is partly attributed to the release of free radicals from activated microglia. Inhibition of free radicals by several anti-oxidants may suppress microglial activation and thus protect neuronal cell death $[19,20]$. DPPH free radical scavenging assay is one of the widely used methods for screening the antioxidant activities in a relatively short period of time. Earlier report indicated an array of antioxidant polyphenolic compounds in I. dentata extract $[5,6]$. Supporting the earlier published works in our present study ID-EA exhibited strong antioxidant activity by significantly scavenging the DPPH free radicals in a concentration dependent manner.

\section{CONCLUSION}

On the basis of the current results, it is suggested that ID-EA extract significantly inhibits neuroinflammatory responses in LPS-stimulated BV-2 microglial cells. This inhibition might be via suppression of NF-kB activation pathways. Further, the antioxidant actions of ID-EA might also be involved in delivering such potent antineuroinflammatory actions. Therefore, ID-EA extract can be developed as a therapeutic agent in the treatment of microglia-mediated neuroinflammatory disease.

\section{REFERENCES}

1. Block ML, Zecca L, Hong JS. Microglia-mediated neurotoxicity: uncovering the molecular mechanisms. Nature Reviews. 2007; 8: 57-69.

2. McGeer EG, McGeer PL. Inflammatory processes in Alzheimer's disease. Prog Neuropsychopharmacol Biol Psychiatry. 2003: 27; 741-749.

3. Kleinert H, Pautz A, Linker K, Schwarz PM. Regulation of the expression of inducible nitric oxide synthase. Eur J Pharmacol 2004:500; 255-266.

4. Ahn E, Bang M, Song M. Cytotoxic and ACATinhibitory sesquiterpene lactones fromthe root of Ixeris dentata forma albiflora. Arch Pharm Res 2006; 29: 937-941.

5. Hong S, Jeong D, Kim K, Hwang E. The Composition of the Root of Ixeris dentata var. albiflora Nakai. and Cell Viability and DPPH Radical Scavenging Activities of its Extract. Korean J Nutr 2010; 43: 105-113.

6. Kim MJ, Kim JS, Jeong DM, Ham SS, Yu CY. Effect of antioxidant, antimutagenicity and anticancer of root extract from Ixeris dentata Nakai. Korean J Medicinal Crop Sci 2002; 10: 222-229.

7. Choi JS, Chung HY, Young HS. A preliminary study on hypocholesterolemic and hypoglycemic activities of some medical plants. Korean J Phamacogn 1990; 21: 153-155

8. Oh SH, Sung $\mathrm{TH}$, Kim MR. Ixeris dentata extract maintains glutathione concentrations in mouse brain tissue under oxidative stress induced by kainic acid. $J$ Med Food 2003; 6: 353-358.

9. Nanjo $F$, Goto $K$, Seto $R$, Suzuki M. Scavenging effects of tea catechins and their derivatives on 1,1-diphenyl2-picrylhydrazyl radical. Free Radic Biol Med 1996; 21: 895-902.

10. Kim BW, Koppula S, Kim IS, Lim HW. Antineuroinflammatory activity of Kamebakaurin from Isodon japonicus via inhibition of c-Jun $\mathrm{NH}$-terminal kinase and p38 mitogen-activated protein kinase pathway in activated microglial cells. J Pharmacol Sci 2011; 116: 296-308. 
11. Green LC, Wagner DA, Glogowski J, Skipper $P L$, Wishnok JS, Tannenbaum SR. Analysis of nitrate, nitrite, and [15N] nitrite in biological fluids. Anal Biochem 1982; 126: 131-138.

12. Choi DK, Koppula S, Suk K. Inhibitors of Microglial Neurotoxicity: Focus on Natural Products. Molecules 2011; 16: 1021-1043.

13. Xie QW, Kashiwabara $Y$, Nathan C. Role of transcription factor NF-kappa B/Rel in induction of nitric oxide synthase. J Biol Chem 1994; 269: 4705-4708.

14. Ock J, Kim S, Yi KY, Kim NJ, Han HS, Cho JY, Suk K. Biochem Pharmacol. 2010; 79: 596-609.

15. Park GH, Jeon SJ, Ko HM, Ryu JR, Lee JM, Kim HY, Han SH, Kang YS, Park SH, Shin CY, Ko KH. Activation of microglial cells via protease-activated receptor 2 mediates neuronal cell death in cultured rat primary neuron. Nitric Oxide 2010; 22: 18-29.
16. Minghetti L. Cyclooxygenase-2 (COX-2) in inflammatory and degenerative brain diseases. J Neuropathol Expl Neurol 2004; 63: 901-910.

17. Gosselin D, Rivest S. Role of IL-1 and TNF in the brain: Twenty years of progress on a Dr. Jekyll/Mr. Hyde duality of the innate immune system. Brain Behav Immun 2007; 21:281-289.

18. Kumar A, Takada Y, Boriek AM, Aggarwal BB. Nuclear factor-kappaB: Its role in health and disease. $\mathrm{J} \mathrm{Mol}$ Med 2014; 82: 434-448.

19. Hsiao G, Fong TH, Tzu NH, Lin KH, Chou DS, Sheu JR. $A$ potent antioxidant, lycopene, affords neuroprotection against microglia activation and focal cerebral ischemia in rats. In Vivo 2004; 18: 351-356.

20. Li Y, Liu L, Barger SW, Mrak RE, Griffin WS. Vitamin E suppression of microglial activation is neuroprotective. J Neurosci Res 2001; 66: 163-170. 